\title{
The cost-effectiveness of routine versus restrictive episiotomy in Argentina
}

\author{
Josephine Borghi, MSc, ${ }^{\mathrm{a} J u l i a}$ Fox-Rushby, PhD, ${ }^{\mathrm{b}}$ Eduardo Bergel, MSc, ${ }^{\mathrm{b}}$ Edgardo Abalos, MD, \\ Guy Hutton, $\mathrm{PhD}, \mathrm{b}$ and Guillermo Carroli, $\mathrm{MD}^{\mathrm{c}}$ \\ London, United Kingdom, and Rosario, Argentina
}

\begin{abstract}
OBJECTIVE: This article provides the estimates of the cost implications of switching from routine to restrictive episiotomy in 2 provinces in Argentina (Santa Fe and Salta) from the viewpoint of the health provider. STUDY DESIGN: A decision-tree model was constructed that used the probabilities and patient outcomes (the results of a trial in Argentina), resource use, cost, and local epidemiologic data from interviews with obstetricians in the selected provinces and from literature reviews. Probabilistic sensitivity analysis was conducted, which provided $90 \%$ confidence ranges for the cost data.

RESULTS: For each low-risk vaginal delivery, there is a potential reduction in provider cost of $\$ 20.21$ (range, \$19.36-\$21.09) with a restrictive policy of episiotomy in Santa Fe province and a reduction of \$11.63 (range, \$10.89-\$12.42) in Salta province.

CONCLUSION: The more effective policy of restrictive episiotomy is also less costly than that of routine episiotomy. The results are robust and consistent in both provinces. Further research is required to confirm the appropriate indications for episiotomy and the impact on outcomes of variations in episiotomy cost rates.
\end{abstract} (Am J Obstet Gynecol 2002;186:221-8.)

Key words: Cost, effectiveness, episiotomy, Argentina, decision tree

Episiotomy is usually performed with the intention of reducing the likelihood of severe perineal tears ${ }^{1-3}$ and reducing the risk of fetal trauma. Episiotomy is one of the most commonly performed surgical procedures, although it was introduced without strong scientific evidence of its effectiveness. ${ }^{4}$ In Argentina, episiotomy is a routine intervention in most nulliparous and primiparous births. ${ }^{5}$ However, the benefits of routine episiotomy practice have been challenged,2,6 and the Cochrane systematic review 6 concluded that a policy of restrictive, compared with routine, episiotomy involved significantly less trauma to the posterior perineum, fewer sutures, and fewer healing complications. The trial in Argentina, ${ }^{7}$ which was included in the review, concluded that "a policy of routine episiotomy should be abandoned and rates above $30 \%$ cannot be justified."

From the Maternal and Child Epidemiology Unit and the Health Policy Unit, ${ }^{b}$ London School of Hygiene and Tropical Medicine; and the Centro Rosarino de Estudios Perinatales (CREP). ${ }^{c}$

Supported in part by the UK Department for International Development (J. B.) and by the Global Forum for Health Research, Geneva, Switzerland.

Received for publication December 19,2000; revised April 20, 2001; accepted August 20,2001.

Reprint requests: Julia Fox-Rushby, Health Policy Unit, London School of Hygiene and Tropical Medicine, Keppel St, London WC1E 7HT. E-mail: julia.fox-rushby@lshtm.ac.uk.

Copyright 2002, Mosby, Inc. All rights reserved.

$0002-9378 / 2002 \$ 35.00+0 \quad \mathbf{6 / 1 / 1 1 9 6 3 2}$

doi:10.1067/mob.2002.119632
Given the proven benefits of restricting episiotomy practice, policy makers are now interested in quantifying the potential savings from a change in practice. In Venezuela and Brazil, the estimate was that a switch to a restrictive episiotomy policy could potentially save providers between $\$ 6.50$ and $\$ 12.50$ in suture materials for every vaginal birth without episiotomy, which indicates that the economic implications of a change in practice could be substantial. ${ }^{6}$ However, the scope of this cost analysis was narrow, focusing only on suture material.

The overall aim here was to estimate the cost-effectiveness of a switch from a policy of routine episiotomy to restrictive episiotomy in 2 case study provinces of Argentina (Santa Fe and Salta) that had large differences in disease burden and economic indicators. This study includes not only the cost of suture material but also the cost of any other resources that are associated with the practice of episiotomy.

The specific objectives of the study were to (1) develop a decision tree to model the costs and costeffectiveness of a switch from routine episiotomy to restrictive episiotomy in the populations of 2 provinces of Argentina, (2) develop a model that was based on probabilistic sensitivity analysis to account for the effects of the uncertainty of costs and effects, and (3) examine the impact of alternative assumptions of the model and raise hypotheses about causes of variation in cost-effectiveness. 


\section{Material and methods}

Scope of the study. This study focuses on the practice of episiotomy for low-risk vaginal delivery. Assisted vaginal deliveries (forceps or vacuum) were not considered because the effectiveness of an episiotomy policy is not established for these procedures and because the associated resource use is expected to be very different. Furthermore, assisted deliveries occur in only a small proportion of cases, and there was no significant difference between trial arms (restrictive, $2.54 \%$; routine, $3.20 \%$ ).

Argentina was selected because of the wide range of disease burdens and health care settings within the country, which enabled the estimation of costs in diverse settings; 2 provinces that were representative of this diversity were selected: Santa Fe and Salta.

Effectiveness. Evidence on biologic outcomes was taken from the Argentine Episiotomy Trial, in which routine episiotomy was defined as "complying with traditional hospital procedures," with a corresponding episiotomy rate of $81 \%$. Restrictive practice was defined as intervening in the case of "fetal indications or to prevent a severe perineal tear," with an episiotomy rate of $30 \%$. Only maternal and neonatal outcomes with statistically significant differences (Peto odds ratio) between trial arms were included in the model. The Argentine trial was a large, multicenter study that included hospitals in 3 provinces in Argentina. Hence, it was assumed that the results would be equally relevant to hospitals from different geographic areas (Santa Fe and Salta provinces, in particular).

The rates of episiotomy, the need for suturing, perineal pain, wound dehiscence, and healing complications were significantly lower in the restrictive episiotomy group compared with the routine episiotomy group, ${ }^{7}$ although rates of anterior trauma were significantly lower in the routine group. There was no statistically significant difference between trial arms for all other outcomes.

Resource use and costs. Costs were evaluated from a provider perspective: the municipalities of Rosario (Santa Fe province) and Salta (Salta province). Women's preferences and costs, although an important issue, ${ }^{8-10}$ were not considered here. Resource use and costs were considered up to 1 month after delivery, on the basis of the duration of adverse events in each of the studies included in the Cochrane review. ${ }^{6}$

An obstetrician in the United Kingdom helped to identify the standard treatment path and resources used during and after episiotomy. Subsequently, a questionnaire was developed and distributed to a sample of 7 obstetricians to identify the differences in practice between Santa Fe province and Salta province. Obstetricians were interviewed in large maternity hospitals of similar capacity in Santa Fe province and Salta province.

Resources were classified as staff, medical material, drugs, equipment, and building. Costs of equipment, utilities, and overhead were extracted from an unpublished cost analysis of maternal health services in Rosario, Argentina. ${ }^{11}$ Costs of drugs and medical materials were derived from the national pharmacy price list. The opportunity cost of staff time was approximated by staff salaries. Capital costs were annualized with the use of straight-line depreciation that was based on estimates of life expectancy. All costs are presented in 1999 United States dollars (assuming a nominal exchange rate of US $\$ 1=1$ Peso) and, where necessary, costs were inflated to 1999 prices with the use of the inflation rates for 1997 through 1999.12 Most input prices were set nationally (drug, medical material, and staff); therefore, one price was used for both provinces utilization data that for maternity hospitals in Salta province were unavailable; therefore, overhead costs were assumed to be the same for both provinces. The independent sample $t$ test was used to compare mean costs between routine and restrictive groups and between Santa Fe and Salta provinces.

To structure the problem, a decision tree was constructed, with subjective probabilities that were derived from the Argentine Episiotomy Trial. From the completed questionnaires from obstetricians, resource use and unit costs could be identified for both provinces for each element of the intervention: episiotomy, suturing (with and without episiotomy), adverse events (perineal pain, healing complications, and wound dehiscence). A number of assumptions were formulated and incorporated into the model, on the basis of the questionnaire findings and appear in Appendix 1.

Handling uncertainty. To account for uncertainty regarding many of the cost and effectiveness variables, a probabilistic sensitivity analysis, whereby probability distributions are assigned to the model input, was performed to provide information regarding the range of likely values within which the cost estimate may fall. The model was iterated according to a Monte Carlo sampling type with standard recalculation of expected value until convergence was reached (all output percentages change less than 1.5\%). Palisade @RISK software (version 3.5) was used to perform the simulation. The cost estimates were expressed as probability distributions rather than as single point estimates. ${ }^{13}$ Sensitivity analyses were also performed to test the impact of varying point estimates, for which a probability distribution could not be estimated, on final results. The impact on final results of excluding the opportunity cost of staff time was considered. In addition, the effect of variations in the costs of drugs and medical supplies was also evaluated. Prices of drugs and medical supplies were reduced by $29 \%$ (in line with price lists produced by the Ministry of Health in Mexico) and increased 6-fold (in line with price lists for the United Kingdom produced by the UK charity ECHO International Health Services Limited).* We also considered the

* ECHO was set up to assist health facilities in the developing world to meet their medical supply needs more effectively. 
Table I. Breakdown of costs associated with episiotomy, in US dollars (1999)

\begin{tabular}{lrr}
\hline \multicolumn{1}{c}{ Event } & Province \\
\cline { 2 - 4 } & Santa Fe & Salta \\
\hline Episiotomy (including anesthetic) & 2.60 & 0.73 \\
Suturing with no episiotomy (including anesthetic) & 5.78 & 3.90 \\
Suturing with episiotomy (no anesthetic) & 3.64 & 3.64 \\
Treatment of perineal pain & 7.04 & 0 \\
Treatment of healing complications & 22.70 & 13.86 \\
Treatment of wound dehiscence & 24.39 & 13.86 \\
\hline
\end{tabular}

Table II. Difference in total cost and total effect between control and intervention arms

\begin{tabular}{lccc}
\hline & $\begin{array}{c}\text { Routine episiotomy } \\
(\text { control }[C])\end{array}$ & $\begin{array}{c}\text { Restrictive episiotomy } \\
\text { (intervention }[I])\end{array}$ & Difference (I-C) \\
\hline Total cost per vaginal delivery (US\$; 1999) & & & \\
$\quad$ Santa Fe province* & $64.88(62.19 ; 67.67)$ & $44.66(42.79 ; 46.62)$ & $-20.21(-21.09 ;-19.36)$ \\
$\quad$ Salta province* & $36.06(33.90 ; 38.51)$ & $24.42(22.92 ; 26.14)$ & $-11.63(-10.89 ;-12.42)$ \\
Probability of perineal pain $\dagger$ & $0.42(0.40 ; 0.45)$ & $0.31(0.28 ; 0.33)$ & $0.12(0.10 ; 0.14)^{*}$ \\
Probability of healing complications $\dagger$ & $0.30(0.26 ; 0.34)$ & $0.21(0.17 ; 0.24)$ & $0.09(0.07 ; 0.12)^{*}$ \\
Probability of wound dehiscence $\dagger$ & $0.09(0.07 ; 0.12)$ & $0.04(0.03 ; 0.06)$ & $0.14(0.12 ; 0.16)^{*}$ \\
\hline
\end{tabular}

*The $90 \%$ ranges in which the parameters fell; the ranges given in parentheses are $95 \%$ CIs, with an assumption of the normal distribution of effectiveness results.

†From Carroli G, Belizan J. Episiotomy for vaginal birth (Cochrane review). In: The Cochrane Library, 4, 2001. Oxford: Update Software.

impact on results of the varying episiotomy rates in the routine and restrictive groups.

\section{Results}

The Fig shows the decision-tree model. Attached to each of the branches is a probability of occurrence of each specific event. The probability value that is associated with each event is placed below the branches of the tree and is conditional on the events that occur in the previous branches. Tables A-I through A-V in Appendix 2 show the resources that are used for each activity and the probability distributions around each of the variables that were fed into the model.

The unit costs of episiotomy, suturing, anesthetic usage, and treatment of adverse events are applied to the relevant branches (Table I). Each includes the opportunity costs of staff time and the direct costs of medical material, drugs, equipment, and overhead, as indicated in Appendix 2 (Tables A-I through A-V). Table I shows that the costs that are associated with the treatment of adverse events that resulted from the practice of episiotomy are the most substantial in both provinces. The costs that are associated with episiotomy are consistently higher in Santa Fe province compared with Salta province (Table I). The costs of the treatment of perineal pain are almost zero in Salta province, and the costs that are associated with the administration of anesthetics are also much lower in Salta province, compared with Santa Fe province (Table I).
The average total costs per delivery in the routine and restrictive groups were derived by applying the intermediate costs (Table I) to the relevant branches of the decision tree and rolling back. Table II indicates that, for each low-risk vaginal delivery, there is a potential reduction in cost of \$20.21 (range, \$19.36-\$21.09) with a restrictive policy of episiotomy in Santa Fe province and a reduction of \$11.63 (range, \$10.89-\$12.42) in Salta province. Both reductions are statistically significant $(P=.03$ [Santa $\mathrm{Fe}$ province]; $P=.05$ [Salta province]). The difference between provinces is not significantly different in statistical terms $(P=.17)$. Drugs and medical materials are the biggest contributor to cost $(99 \%$ of the total cost for an episiotomy and $72 \%$ of the total cost for suturing). The estimated value of staff time accounts for almost the entire remainder of the cost.

If the value of staff time is not included in the model for Santa Fe province, the results are robust in both Santa Fe and Salta provinces. When prices of drugs and medical material are reduced by $29 \%$, the total cost per delivery in the routine group in Santa Fe province falls to $\$ 49.45$ (range, \$44.51-\$54.40) compared with \$33.82 (range, $\$ 30.44-\$ 37.20$ ) in the restrictive group (a reduction of $\$ 15.63$ [range, \$14.07-\$17.19]). Under the same change in prices for Salta province, the total cost per delivery in the routine group falls to $\$ 29.19$ (range, \$26.27-\$32.11) compared with $\$ 19.59$ (range, $\$ 17.63-\$ 21.55$ ) in the restrictive group (a reduction of $\$ 9.60$ [range, \$8.64$\$ 10.56]$ ). When the price of drugs and material are in- 


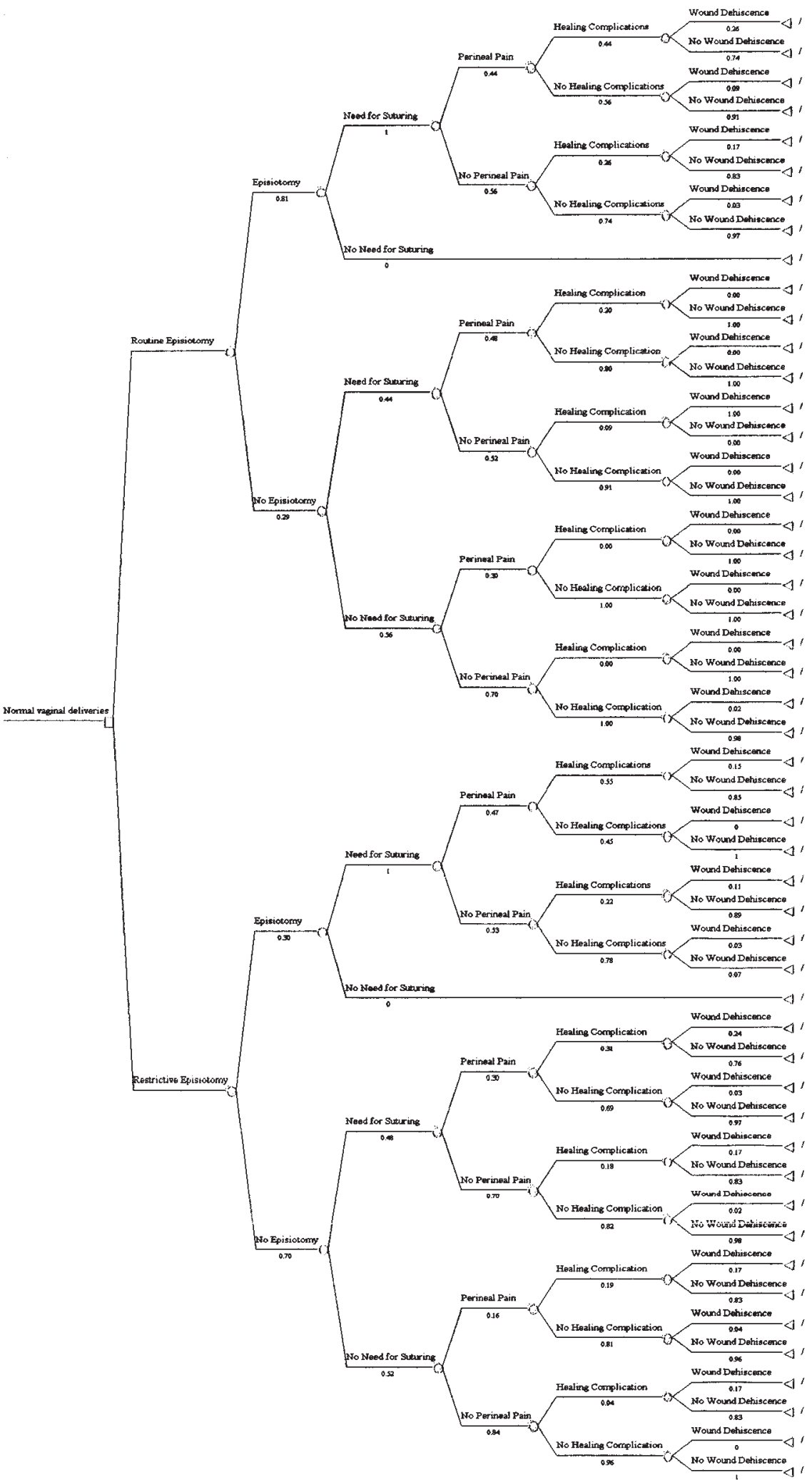

Figure. Decision-tree model shows the treatment path for women with or without episiotomy, depending on the episiotomy policy.

creased 6-fold, the difference in the total cost per delivery between the routine and restrictive groups increases to
$\$ 99.05$ (range, $\$ 89.15-\$ 108.96$ ) in Santa Fe province and to $\$ 46.44$ (range, $\$ 41.80-\$ 51.08$ ) in Salta province. 
The impact of changes in the observed episiotomy rates under routine and restrictive policies was also examined. In Santa Fe province, if routine practice were characterized by episiotomy rates as low as $51 \%$ (compared with $44 \%$ for the restrictive practice), the total cost in the routine group would fall to $\$ 53.13$ (range, $\$ 50.99$ $\$ 55.39$ ) compared with $\$ 50.33$ (range, $\$ 48.19-\$ 52.61$ ) in the restrictive group; the difference reduces to $\$ 2.80$ (range, \$2.64-\$2.96) per low-risk vaginal delivery. With the use of the same rates in Salta province, policy options are now almost equal, with a difference of only $\$ 0.57$ (range, \$0.49-\$0.67).

\section{Comment}

The Argentine Episiotomy Trial showed that a restrictive episiotomy policy at $30 \%$, compared with a routine episiotomy policy at $81 \%$, was more effective. This study has shown that a policy of restrictive episiotomy is also significantly less costly. The results, which reflected the cost of all resources that are associated with the practice of episiotomy, were robust and consistent in 2 provinces that had differing population characteristics in terms of income and maternal death. Given this result of strong dominance, neither the provision of incremental costeffectiveness ratios nor the translation of effectiveness to health state utilities, such as disability-adjusted life years, adds any more information to the results. ${ }^{14}$

The number of live births for 1996 was estimated at 55,192 and 24,074 for Santa Fe province and Salta province, respectively. ${ }^{15}$ Assuming a cesarean delivery rate of $20 \%,{ }^{12}$ the number of vaginal deliveries was approximately 11,038 and 4,815 for each province, respectively. Hence, by switching from routine to restrictive episiotomy, savings could be made at the provincial level of $\$ 223,086$ and $\$ 55,996$ for Santa Fe province and Salta province, respectively. However, although immediate savings could be made in terms of medical supplies and drugs, after the switch in policies, savings in terms of staff and overhead would only occur in the medium to long run. For staff, savings will only be generated if they can successfully be used in an alternative function (eg, if the time saved from the reduced number of episiotomies is used as additional patient contact time). We saw that drugs and medical supplies represent $99 \%$ of the total cost; hence, we can assume that $99 \%$ of the savings would occur in the short term.

However, this estimate of savings does not include the cost of the implementation of the policy change (the restriction of the practice of episiotomy, in terms of, for example, consensus building between policy makers, public and private-sector health care workers, the publication and dissemination of amended treatment guidelines, and the establishment of an amended training protocol). These actions may have significant associated costs that should be borne in mind.
Costs that are related to episiotomy were substantially lower in Salta province compared with Santa Fe province because of differences in treatment practice. In Salta province, local rather than epidural anesthetic is administered to women during vaginal birth, and perineal pain is not treated (although it would be treated if it was a symptom of healing complications/wound dehiscence). Similarly, drug treatments are less costly for other adverse events in Salta province than they are in Santa Fe province. Given that the routine rate of episiotomy is substantially higher than $51 \%$ in all provinces in Argentina, ${ }^{16}$ it would therefore seem appropriate to suggest that the effectiveness results can be generalized for the whole of Argentina and that costs will reduce, although the size of the cost reduction may vary by province.

However, the results of the sensitivity analysis indicate that, if the routine and restrictive groups were to be defined by episiotomy rates of $51 \%$ and $44 \%$, respectively, and if everything else were equal, the difference in total treatment cost between the groups would reduce substantially. Hence, results for other countries will be dependent on how closely the episiotomy rates, treatment practice, resource costs, and need for episiotomy match the assumptions of this model.

Furthermore, it is important to determine the optimal episiotomy rate for a specific population, but this study did not consider a definition that could reliably fall below a restrictive policy of $<30 \%$. Therefore, although episiotomy rates of $<30 \%$ may reduce costs further, it is possible that they may also result in detrimental fetal and/or neonatal outcomes for those cases in which an episiotomy was clearly indicated but not performed. Further research is required to determine optimal rates of episiotomy in relation to clinical indicators of need. This would allow an investigation of the cost per true/false positive/negative result and a reassessment of the most cost-effective rate of episiotomy. Parity is one indicator of clinical need, with nulliparous and primiparous women being at higher risk than multiparous women and having a greater "need" for an episiotomy. ${ }^{6}$ For example, in Santa Fe province, the episiotomy rates in primiparous women compared with multiparous women were $75 \%$ and $14 \%$, respectively; in Salta province, the rates were $74 \%$ and $5 \%$, respectively.

This study included only those outcomes that showed a statistically significant difference between trial arms. It is possible that outcomes for which there were not statistically significant differences in effectiveness do have a statistically significant impact on costs (either increasing or decreasing). Furthermore, resource use consequences that were associated with the treatment of adverse events were only considered up to 1 month after delivery, because all statistically significant outcomes occurred within this period. However, this did not enable the evaluation of the costs that were associated with the increased longterm risk of pelvic floor dysfunction when an episiotomy 
is not performed. The Cochrane review ${ }^{6}$ indicates that there is no significant difference between arms in terms of urinary incontinence. However, a longer-term trial is required to provide an accurate measure of the impact of episiotomy on the other clinical conditions that define pelvic floor dysfunction.

The scope of this study did not enable the consideration of the costs that were associated with episiotomy for assisted deliveries. Finally, another pressing issue, which was not considered here, is the evaluation of which episiotomy technique (mediolateral or midline) provides the best outcome. ${ }^{17}$

Overall, this study showed that a restrictive episiotomy policy is more effective and less costly than a routine episiotomy policy in Argentina. These results should help policy makers to promote changes in current practice among birth attendants. Further research is required to investigate the impact of the exclusion of outcomes that are not significantly different between arms from costing and cost-effectiveness analyses and to ascertain the appropriate indications for episiotomy in different settings.

We thank Cam Donaldson for his comments at the UK Health Economics Study Group Meeting in Nottingham, UK.

\section{REFERENCES}

1. Ould F. A treatise of midwifery. London: J Buckland; 1741. p. $145-6$.

2. Thacker SB, Banta HD. Benefits and risks of episiotomy: an interpretative review of the English language literature, 1860-1980. Obstet Gynecol Surv 1983;38:322-38.

3. Conduct of normal labor and delivery. In: Cunningham FG, MacDonald PC, Gant NF, Leveno KJ, Gilstrap LC III, editors. Williams obstetrics. 19th ed. Norwalk (CT): Appleton and Lange; 1993. p. 371-93.

4. Lede R, Belizan JM, Carroli G. Is routine use of episiotomy justified? Am J Obstet Gynecol 1996;174:1399-402.

5. Lede R, Moreno M, Belizan JM. Reflexiones acerca de la indicacion rutinaria de la episiotomia. Sinopsis Obstet Ginecol 1991;38:161-6.

6. Carroli G, Belizan J. Episiotomy for vaginal birth (Cochrane review). In: The Cochrane Library, 4. Oxford: Update Software; 2001.

7. Argentine Episiotomy Trial Collaborative Group. Routine vs selective episiotomy: a randomised controlled trial. Lancet 1993;42:1517-8.

8. Kitzinger S. Episiotomy: physical and emotional aspects. London: The National Childbirth Trust; 1981a.

9. Kitzinger S. Some women's experience of episiotomy. London: The National Childbirth Trust; 1981b.

10. Klein M. Rites of passage: episiotomy and the second stage of labour. Can Fam Physician 1988;34:19-25.

11. Borghi J, Bastus S, Belizan M, Giordano D, Abalos E, Fox-Rushby $\mathrm{J}$, et al. Costs of antenatal and related care in Argentina: a costminimisation analysis of the new WHO antenatal care package. Final Report submitted to WHO; 2000. Copies of the report are available from the authors.

12. Federal Reserve Bank of Minneapolis. Consumer price index 1913 - Available at: http://mineapolisfed.org/economy/calc/ hist1913.html

13. Goodman C, Coleman PG, Mills AJ. Cost-effectiveness of malaria control in sub-Saharan Africa. Lancet 1999;354:378-85.
14. Drummond MF, O'Brien B, Stoddart GL, Torrance GW. Methods for the economic evaluation of health care programmes. 2nd ed. Oxford (UK): Oxford University Press; 2000.

15. Pan American Health Organisation. Health in the Americas. vol 1; scientific publication No. 569. Washington (DC): Pan American Sanitary Bureau; 1998.

16. Diaz AC, Schwarcz R, Diaz Rosello J, Simini F, Lopez R, Martell $\mathrm{M}$, et al. Sistema informatico perinatal. Montevideo: CLAP; 1991. Publicacion ciertifica No.: 1203.

17. Thacker SB. Midline versus mediolateral episiotomy [editorial]. BM J 2000;320:1615-6.

\section{Appendix 1}

Assumptions included in the decision-tree model

- The outcome "need for suturing perineal trauma," which was measured during the trial, is considered rather than "anterior and posterior trauma." Perineal trauma does not always require suturing, so the "need for suturing" variable enables the measurement of resource use in terms of suture material.

- All women who undergo an episiotomy require suturing.

- Adverse events can occur from perineal pain alone, from perineal pain and healing complications, from perineal pain and wound dehiscence, from perineal pain and healing complications and wound dehiscence, from healing complications alone, from healing complications and wound dehiscence, or from wound dehiscence alone. (Although the outcomes themselves were identified from the Argentine trial, the questionnaire enabled us to justify this classification.)

- Women who experience perineal pain alone after discharge do not require readmission to hospital.

- One percent of women who experience wound dehiscence and/or healing complications will be readmitted to the hospital for 2 to 7 days.

- One percent of women who experience wound dehiscence and/or healing complications will require resuturing.

- The intervention does not affect length of stay.

- For a woman who experiences healing complications and wound dehiscence, we considered only the cost of treating the wound dehiscence. Because the treatment paths are similar, this avoided double counting.

- Absorbable suture material is used to perform suturing; therefore, the costs that were associated with the removal of suture material were not considered.

- In Salta province, no epidural anesthetic is administered for low-risk vaginal delivery (only local anesthetic); no treatment is provided to patients who experience perineal pain alone; wound dehiscence and healing complications are treated in the same way. 


\section{Appendix 2}

Input into probabilistic sensitivity analysis. The tables that follow contain the variables, probability distribution, and distribution parameters for episiotomy alone, suturing alone, the treatment of adverse events (perineal pain, healing complications, and wound dehiscence), and effectiveness measures.

Table A-I. Model variables for practice of episiotomy alone (costs in US dollars, 1999)

\begin{tabular}{|c|c|c|}
\hline Model variables & Probability distribution & Distribution parameters \\
\hline \multicolumn{3}{|l|}{ Staff } \\
\hline Probability obstetrician; probability resident & $\begin{array}{l}\text { Triangular } \\
\text { 1-(probability obstetrician) }\end{array}$ & Mode: 0.50 (range, $0.3-0.7$ ) \\
\hline \multicolumn{3}{|l|}{ Salary $(\$)$} \\
\hline Obstetrician $/ \mathrm{min}$ & Point estimate & 0.08 \\
\hline Resident/min & Point estimate & 0.05 \\
\hline \multicolumn{3}{|l|}{ Drugs and medical material } \\
\hline Probability of an epidural anesthetic (Santa Fe) & Triangular & Mode: 0.07 (range, 0.06-0.1) \\
\hline Probability of an epidural anesthetic (Salta) & Point estimate & 0.0 \\
\hline Lidocaine $2 \% *(\$)$ & Point estimate & 0.12 \\
\hline Bupivicaine $0.5 \%+(\$)$ & Point estimate & 18.10 \\
\hline Fentanyl citratet $(\$)$ & Point estimate & 2.20 \\
\hline Needle $(\$)$ & Point estimate & 0.07 \\
\hline Syringe $(\$)$ & Point estimate & 0.08 \\
\hline Cathetert $(\$)$ & Point estimate & 1.78 \\
\hline Trocart $(\$)$ & Point estimate & 0.03 \\
\hline Self-adhesive cloth $†(\$)$ & Point estimate & 0.29 \\
\hline \multicolumn{3}{|l|}{ Capital items } \\
\hline Equipment (scissors) $+(\$)$ & Point estimate & 0.24 \\
\hline Overhead costs (building and utilities/min) $§(\$)$ & Triangular & Mode: 0.01 (range, 0.007-0.012) \\
\hline Duration of procedure (min) & Triangular & Mode: 3.89 (range, 2-7) \\
\hline
\end{tabular}

*Used for both epidural and local anesthetic; probability of use is 1.00.

†Used for epidural anesthetic alone.

$\ddagger$ The distribution around cost reflects 2 alternative methods of cost that were considered. Scissors are used only for episiotomy (no other intervention) and are cleaned at the end of each delivery by sterilization. The first cost method consists of evaluating the scissors by valuing the sterilization pack used to sterilize the scissors before the next delivery (data obtained from antenatal care costing). The second method consists of the annualized value of the scissors (assuming a linear discount rate and an expected length of life of 10 years).

§The range values represent costs in a delivery room of a generalist hospital with a maternity ward and a large maternity hospital in Rosario, respectively. ${ }^{12}$

Table A-II. Model variables for practice of suturing in Salta and Santa Fe provinces alone (costs in US dollars, 1999)

\begin{tabular}{|c|c|c|}
\hline Model variables & Probability distribution & Distribution parameters \\
\hline \multicolumn{3}{|l|}{ Staff } \\
\hline Probability obstetrician; probability resident & $\begin{array}{l}\text { Triangular 1-(probability } \\
\text { obstetrician) }\end{array}$ & Mode: 0.50 (range, $0.3-0.7$ ) \\
\hline \multicolumn{3}{|l|}{ Salary $(\$)$} \\
\hline Obstetrician/min & Point estimate & 0.08 \\
\hline Resident/min & Point estimate & 0.05 \\
\hline \multicolumn{3}{|l|}{ Drugs and medical materials $(\$) *$} \\
\hline Iodine solution $(10 \mathrm{~mL})$ & Point estimate & 0.36 \\
\hline Needle for suturing & Point estimate & 0.24 \\
\hline Surgical catgut (No. 0) & Point estimate & 1.60 \\
\hline Surgical swabs $(\times 1)$ & Point estimate & 0.04 \\
\hline Tray for suture set & Point estimate & 0.07 \\
\hline Needle holder & Point estimate & 0.07 \\
\hline Forceps for dissection & Point estimate & 0.24 \\
\hline \multicolumn{3}{|l|}{ Capital items } \\
\hline Overhead costs (building and utilities/min) $(\$)$ & Triangular & Mode: 0.01 (range, 0.007-0.012) \\
\hline Duration of procedure (min) & Triangular & Mode: 8.06 (range, 5-25) \\
\hline
\end{tabular}

*Prices obtained from national pharmacy price list (LEM). 
TABLE A-III. Model variables for treatment of adverse events: perineal pain (costs in US dollars, 1999)†

\begin{tabular}{lcc}
\hline Model variables for perineal pain & Probability distribution & Distribution parameters \\
\hline Acetaminophen $500 \mathrm{mg}^{*}(\$)$ & Point estimate & 0.09 \\
Ibuprofen $200 \mathrm{mg}^{*}(\$)$ & Point estimate & 0.15 \\
Naproxen $250 \mathrm{mg}^{*}(\$)$ & Point estimate & 0.19 \\
Tablets $(\mathrm{n})$ & Triangular & Mode: $31.92($ range, $30-40)$ \\
Acetaminophen/ibuprofen & Point estimate & 40 \\
Naproxen & Point estimate & 0.08 \\
Probability & Point estimate & 0.84 \\
Acetaminophen/ibuprofen & & \\
Naproxen & & \\
\hline
\end{tabular}

*Prices obtained from national pharmacy price list (LEM).

$\dagger$ As there is no treatment in Salta for perineal pain, this table is for Santa Fe only.

TABLE A-IV. Model variables for treatment of adverse events in Santa Fe and Salta provinces: healing complications and wound dehiscence (costs in US\$1999)

\begin{tabular}{|c|c|c|}
\hline Model variables & Probability distribution & Distribution parameters \\
\hline \multicolumn{3}{|l|}{ Medical materials } \\
\hline Iodine solution $(10 \mathrm{~mL})(\$)$ & Point estimate & 0.36 \\
\hline Cotton $(\$)$ & Point estimate & 0.04 \\
\hline Quantity: iodine solution/cotton (Santa Fe) & Triangular & Mode: 32.10 (range, $30-40$ ) \\
\hline Quantity: iodine solution/cotton (Salta) & Triangular & Mode: 5.93 (range, 5-7) \\
\hline \multicolumn{3}{|l|}{ Drugs Santa Fe } \\
\hline Cefalexine $500 \mathrm{mg}(\$)$ healing complications & Point estimate & 0.15 \\
\hline Cefalexine $1000 \mathrm{mg}(\$)$ wound dihiscence alone & Point estimate & $\$ 0.29$ \\
\hline Quantity cefalexine tablets & Triangular & Mode: 31.46 (range, 28-40) \\
\hline \multicolumn{3}{|l|}{ Drugs Salta } \\
\hline Klosidol (\$) & Point estimate & 0.09 \\
\hline Amoxicillin/clavonic acid $(125 \mathrm{mg})(\$)$ & Point estimate & 0.14 \\
\hline Quantity (tablets) & Triangular & Mode 22.57 (range 15-28) \\
\hline \multicolumn{3}{|l|}{ Probability } \\
\hline Probability cefalexine $500 \mathrm{mg}$ & Point estimate & 0.67 \\
\hline Probability cefalexine $1000 \mathrm{mg}$ & Point estimate & 0.17 \\
\hline Probability iodine and cotton & Point estimate & 1 \\
\hline Probability readmission/resuturing & Triangular & Mode: 0.01 (range, $0-0.02$ ) \\
\hline \multicolumn{3}{|l|}{ LOS and other costs } \\
\hline Duration of stay $(d)$ & Triangular & Mode: 3.97 (range, 2-7) \\
\hline Cost resuturing & Triangular & Mode: 4.51 (range, 42.9-5.23) \\
\hline Cost inpatient ward $/ \mathrm{d}$ & Triangular & Mode: 94.28 (range, 85.59-144.84) \\
\hline
\end{tabular}

Table A-V. Model variables for effectiveness measures in Santa Fe and Salta provinces

\begin{tabular}{|c|c|c|}
\hline Model variables & Probability distribution & Distribution parameters \\
\hline \multicolumn{3}{|l|}{ Probability of perineal pain at discharge } \\
\hline Routine group & Triangular & Mode: 0.41 (range, $0.40-0.45$ ) \\
\hline Restrictive group & Triangular & Mode: 0.29 (range, $0.28-0.33$ ) \\
\hline \multicolumn{3}{|l|}{ Probability of healing complications at 7 days } \\
\hline Routine group & Triangular & Mode: 0.27 (range, $0.26-0.34$ ) \\
\hline Restrictive group & Triangular & Mode: 0.20 (range, $0.17-0.24$ ) \\
\hline \multicolumn{3}{|l|}{ Probability of wound dehiscence at 7 days } \\
\hline Routine group & Triangular & Mode: 0.08 (range, $0.07-0.12$ ) \\
\hline Restrictive group & Triangular & Mode: 0.04 (range, $0.03-0.06$ ) \\
\hline $\begin{array}{l}\text { Probability of maternal sepsis with wound } \\
\text { dehiscence/healing complications }\end{array}$ & Triangular & Mode: $9.09 .10^{-6}\left(\right.$ range, $\left.6.67 .10^{-6}-1.33 .10^{-5}\right)$ \\
\hline
\end{tabular}

Salta province results: Analgesic (Klosidol), \$0.09/tablet; Amoxi-clavulánico $125 \mathrm{mg}, \$ 0.14 /$ tablet; quantity of tablets (triangular distribution): mode, 22.57 (range, 15-28); antiseptic and cotton (see Table A-V); quantity of antiseptic/cotton units (triangular distribution): mode, 5.9 (range, 5-7). 